\title{
EFFECTIVENESS OF CORPORATE GOVERNANCE MECHANISMS: A REVIEW OF THE LITERATURE
}

\author{
Fatimah Mat Yasin, Rusnah Muhamad \& Noor Adwa Sulaiman
}

\begin{abstract}
The key players in corporate governance worldwide are often associated with their potential for enhancing corporate governance practices. This paper presents a review of academic research concerning the effectiveness of these players. Given the importance of these key players, as emphasized by the regulators in most countries, it is crucial to explore their contributions, as documented in the literature. Hence, fundamental insights for analysing the inputs that contribute to their effectiveness, as well as the processes and the outcomes of their effectiveness are discussed in this paper. Furthermore, there is limited evidence that discusses the effectiveness of these players from the perspective of process issues. However, as such studies pertaining to the process issues are important for understanding how they actually perform their roles and enhance their effectiveness, more studies that focus on the process issues are suggested for future research to provide a better understanding of the effectiveness of key players.
\end{abstract}

Keywords: Corporate Governance, Key Players, Effectiveness, Inputs, Process, Outcomes

JEL Classification: G30

\section{Introduction}

The effectiveness of governance key players has been much debated in the literature since the mid-nineties. Their effectiveness was questioned following the financial crisis and the series of corporate collapses that are believed to be the prime factors that contributed to the events (Mitton, 2002; Brown and Caylor, 2006). Despite more than a decade of research, there remains little consensus about the factors that contribute to their effectiveness and how they contribute to the corporate governance practices as we continue to see the conflicting results in the literature (e.g. Bradbury, Mak, and Tan, 2004; Beasley, Carcello, Hermanson, and Neal, 2009; Bame-Aldred, Brandon, Messier, Rittenberg, and Stefaniak, 2013). The corporate governance key players in this study are defined based on the Blue Ribbon Committee (US) and the findings of prior researchers (Cohen, Krishnamoorthy, and Wright, 2004; Gramling,

Corresponding author: Fatimah Mat Yasin is an Accounting Lecturer the Department of Accounting, Kulliyyah of Economics and Management Sciences, International Islamic University Malaysia. Email: fatimahmy@iium.edu.my.

Rusnah Muhamad is an Associate Professor at the Department of Accounting, Faculty of Business and Accountancy, University of Malaya. Email: rusnah@um.edu.my.

Noor Adwa Sulaiman is a Senior Lecturer in the Department of Accounting, Faculty of Business and Accountancy, University of Malaya. Email: adwa@um.edu.my. 
Maletta, Schneider, and Church, 2004) who listed board of directors (including audit committee), the management, internal audit and external audit as the key players in governance.

Although these key players have different functions and handle different parts within a corporation, they have related roles in corporate governance. For example, the board has the role of providing maximum transparency in terms of a company's performance. This includes setting the company's objectives, providing the leadership, supervising the management, and reporting to shareholders on their stewardship (Sarbanes Oxley Act, 2002; Blue Ribbon Committee, 1999). In a related vein, as an operating committee for the board of directors, the audit committee has the role of ensuring the success of corporate governance by monitoring the actions of management in terms of financial reporting as well as internal control (DeZoort, Hermanson, Archambeault, and Reed, 2002). Meanwhile, the internal audit function is in the best position to help other key players to understand the firm's internal control system and risk management (Suwaidan and Qasim, 2010) through its oversight role, and its improvements to the control and monitoring environment (Coram, Ferguson, and Moroney, 2008). Whilst the external audit serves a vital economic purpose and plays an important role in serving the public interest to reinforce trust and confidence in financial reporting.

Consistent with the importance of these key players, researchers have started to investigate their effectiveness. Numerous factors or parameters concerning the effectiveness of these key governance players have been identified and spelt out in the literature. In most cases, the researchers focused on identifying the various characteristics of these mechanisms including independence (Klein, 2002a; Abbott, Parker, Peters, and Raghunandan, 2003; Yatim, Kent, and Clarkson, 2006; Christopher, Sarens, and Leung, 2009), tenure (Carcello and Nagy, 2004; Carey and Simnett, 2006; Knechel and Vanstraelen, 2007), diligence (Carcello, Hermanson, and Riley, 2002; Abbott et al., 2003; Goodwin-Stewart and Kent, 2006; Yatim et al., 2006) and expertise (McDaniel, Martin, and Maines, 2002; Bedard, Chtourou, and Courteau, 2004), which are believed to impinge upon the overall effectiveness of the governance mechanisms. However, the mere existence and the characteristics of the mechanisms alone cannot ensure the effectiveness of the mechanisms without investigating the practical reality of these parties (Gendron, Bedard, and Gosselin, 2004), as, even after the governance reforms, we continue to witness corporate scandals (Chaunrommanee and Swierczek, 2007).

A review of the literature evidences scant knowledge concerning the effectiveness of the governance mechanisms in terms of their practical reality. Hence, studies in this area are important to provide an understanding of the 'black box' of the process (Spira, 2006; Beasley et al., 2009; McNulty, Zattoni, and Douglas, 2013). The knowledge concerning the composition and characteristics of the key players is claimed to exceed the knowledge about their behaviour during the process (McNulty and Pettigrew, 1999). In addition, the participation and contribution of the key players during the process are claimed 
to be the key factors for measuring their effectiveness (Machold and Farquhar, 2013; Pugliese, Nicholson, and Bezemer, 2015), and thus more studies in this area are clearly warranted. This is further supported by Roberts, McNulty, and Stiles (2005) who claimed that researching the governance mechanism processes means revealing how they work and providing a better understanding concerning the concepts of their effectiveness.

The objective of this paper is to evaluate the extent to which prior studies provide evidence about the factors and outcomes of the effectiveness of the governance players, as well as the process to achieve the effectiveness. This study is dedicated to continuing the rich tradition of research in this area to enhance our understanding about the effectiveness of key players in governance. The study also provides avenues for future research along these lines. The rest of the paper is organized as follows. The next section provides fundamental insights into the effectiveness of the governance mechanisms in which the evidence in the literature can be evaluated. Section 3 examines the literature concerning the effectiveness of all key players, which is associated with the inputs, process and outcomes of the effectiveness. More attention is given concerning the studies that focused on the process of the key players in practice since the literature evidences scant knowledge from this perspective. The paper ends with a summary of the evaluation of the evidence and suggestions for future research

\section{Fundamental Insights from the Literature concerning the Effectiveness of the Key Players in terms of Corporate Governance}

The series of corporate collapses in the early 2000s prompted the growing volume of research on corporate governance including the effectiveness of key players in corporate governance. Hundreds of studies in this area have been published and several frameworks have been proposed to achieve a better understanding of the effectiveness of governance players. Notable examples include Carcello, Hermanson, and Ye $(2011)^{2}$ who examined key insights from prior meta-analyses that highlighted the fundamental relation between governance characteristics, and accounting and auditing outcomes. In particular, the analysis revealed the importance of 'good' governance characteristics (e.g. expertise, independence), which contribute to 'good' accounting outcomes (fraudulent financial reporting, restatements, earnings management/accruals quality, accounting conservatism, and accounting quality).

A few other studies that proposed frameworks for understanding governance effectiveness include DeZoort et al. (2002), Turley and Zaman (2004), and Bedard and Gendron (2010) who focused mainly on audit committee effectiveness. In support of Carcello, Hermanson et al. (2011), these studies documented the determinants (e.g. composition, authority, resources and

\footnotetext{
${ }^{2}$ See Carcello, Hermanson et al. (2011) for a detailed discussion of this literature
} 
diligence) and impacts of audit committee effectiveness on various dimensions including audit function, financial reporting quality, corporate performance and others. ${ }^{3}$ The most recent study, by Bame-Aldred et al. (2013), examined the perspective of the internal audit function and external audit effectiveness. The study proposed a framework that emphasized the environmental and internal audit function-specific factors that influence the external auditor's reliance decisions, the nature and extent of the reliance, and the outcomes resulting from the reliance. While providing an understanding concerning the coordination between these two parties in terms of reliance, the study also provided an understanding of the effectiveness of these parties in performing their roles and responsibilities.

These studies highlighted a common important gap in the literature, in that most studies focused on the characteristics and outcomes of the performance of the key players in measuring their effectiveness, which is largely based on publicly available information. While contributing to the knowledge, it is claimed that the findings cannot ensure the effectiveness of the mechanisms without investigating the practical reality of these parties. The governance mechanisms may be established for cosmetic reasons and may be symbolic to meet the requirements of the regulations (Cohen et al., 2004). The literature shows limited understanding concerning the effectiveness of governance players in terms of their surroundings and processes (Pettigrew and McNulty, 1995, 1998; McNulty et al., 2013; Pugliese et al., 2015), which is deemed important to provide better insights into their effectiveness (Gendron et al., 2004; Roberts et al., 2005; Machold and Farquhar, 2013). Furthermore, their effectiveness also differs among market economies, and, hence, one single factor cannot determine their effectiveness (e.g. composition) or have the same significance in all countries as it depends on the culture, regulations and other attributes of the respective country. The lack of current studies that address the process limits our understanding of the effectiveness of the key governance players in practice (McNulty and Pettigrew, 1999; He and Huang, 2011).

To address this gap in the literature, the following section discusses the prior studies that examined and investigated the effectiveness of the key governance mechanisms. Instead of focusing on individual players, this study focuses simultaneously on the effectiveness of all key players (e.g. board of directors, audit committee, internal audit function and external audit). Based on a review of the literature, three perspectives were developed, comprising the inputs, process and outcomes. These fundamental elements of effectiveness are used to evaluate the evidence associated with the effectiveness of the key players in governance.

\footnotetext{
${ }^{3}$ See DeZoort et al. (2002); Turley and Zaman (2004); and Bedard and Gendron (2010), for a detailed discussion
} 


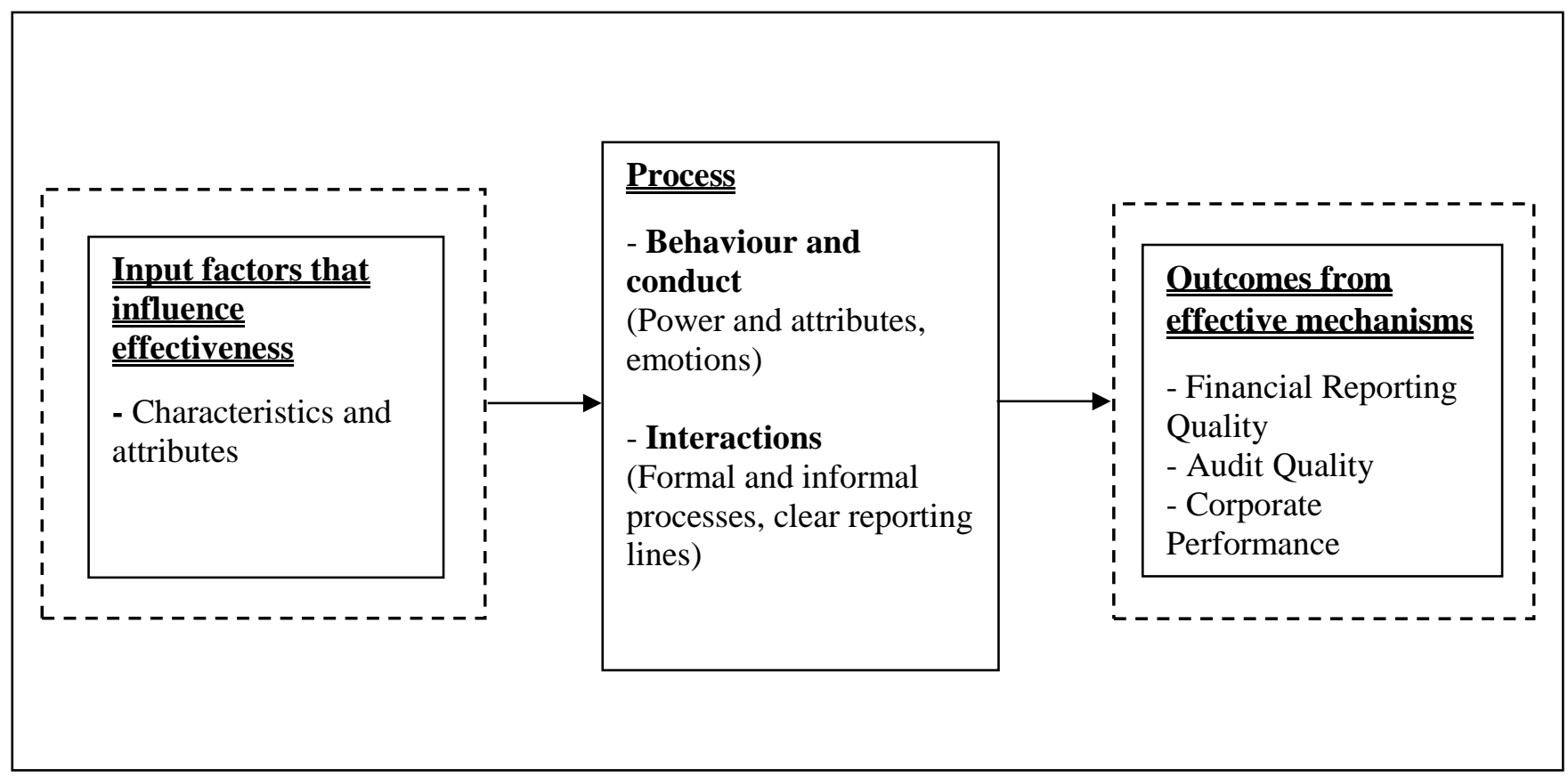

Figure 1: Fundamental Findings from the Literature concerning Insights into the Effectiveness of Corporate Governance Mechanisms 
Figure 1 above illustrates that the composition, characteristics and attributes of the key governance mechanisms are the important elements that the mechanisms need to have to achieve their effectiveness. These elements should be supplemented by appropriate behaviour and conduct as well as the interactions between the mechanisms that can further enhance their effectiveness. Their willingness to use the inputs that they have is vital for ensuring their effectiveness. Accordingly, the effects of the inputs and the processes carried out in the practice are revealed in the outcomes.

\section{Synthesis of the Extant Literature on the Effectiveness of Corporate Governance Mechanisms}

While the literature evidences a lack of studies that focus on the process for understanding the effectiveness of governance players, more attention is given to the studies that investigate the practical reality of the players. The following subsections briefly discuss the inputs and outcomes perspectives and largely focus on the process perspective to explore the effectiveness of the players in the literature.

\subsection{Inputs and Outcomes}

The inputs to the effective governance mechanisms in the literature are mostly related to certain characteristics or attributes of the mechanisms. The characteristics and attributes in the literature include their existence, independence, type of firm, objectivity, competence, expertise, meeting frequency and tenure (Clark, Gibbs, and Schroeder, 1981; Albrecht, Howe, Schueler, and Stocks, 1988; Beattie and Fearnley, 2002; Klein, 2002a; Stewart and Munro, 2007; Christopher et al., 2009). For example, it is expected that independence and other composition characteristics may determine the effectiveness of the governance mechanisms in their monitoring functions and their oversight roles (Jonh and Senbet, 1998). In fact, Klein (2002a) claimed that board members monitoring functions in the corporate financial accounting process is a critical antecedent of its effectiveness. This is supported by Carcello et al. (2002), and Yatim et al. (2006) who documented that boards that meet frequently are likely to be better informed and more diligent in performing their monitoring roles. Similarly, Albrecht et al. (1988) documented that an organization with a capable leadership in terms of a chief of the internal audit function is likely to have an effective internal audit function.

Meanwhile, the outcomes perspective focuses on the impact of the effectiveness of the governance mechanisms on several areas. Among the outcomes of the performance that have been addressed in the literature are corporate performance, financial reporting quality and auditing quality (Beasley, Carcello, Hermanson, and Lapides, 2000; Bailey, Gramling, and Ramamoorti, 2003; Gramling et al., 2004; Destefanis and Sena, 2007; Carcello, Hermanson et al., 2011; Misangyi and Acharya, 2014). For example, both players - board of directors and audit committee - have a potential contribution 
for improving financial reporting (Marsh and Powell, 1989) through their monitoring responsibility of the accounting processes, and compliance with the corporate legal and ethical standards (Turley and Zaman, 2004). It also evident that audit committees have an impact on the internal audit function, including internal controls and risk management (Zaman, 2001), thereby illustrating the effectiveness of audit committees.

Most of the studies in the literature have been designed to examine the associations between the characteristics of governance mechanisms and various outcomes in order to appreciate their effectiveness (e.g. Beasley et al., 2000; Klein, 2002a; Abbott, Parker, and Peters, 2004). For example, Gul and Goodwin (2010) documented that board meetings have a negative relationship with audit fees, which indicates higher audit quality. Consistent with prior studies (Bedard et al., 2004; Hsu, 2008), the findings also show that audit committee financial expertise can influence the audit quality in that specific knowledge, particularly financial, is necessary for the audit committee to perform its monitoring role and develop better governance. The findings support prior studies (Carcello et al., 2002; Salleh, Steward, and Manson, 2006; Yatim et al., 2006) that found that firms with good corporate governance attributes (e.g. independence, expertise and diligence) demand higher audit quality, resulting in higher external audit fees.

Focusing on the internal audit function, Coram et al. (2008) demonstrated that the existence of the internal audit function is more likely to detect the misappropriation of assets and thus reduce management fraud. In a related vein, Prawitt, Smith and Wood (2009) claimed that the existence of the internal audit function could promote greater transparency, and, accordingly, the internal audit function may reduce the tendency of the management to manipulate earnings.

The recent work by Krishnamoorthy and Maletta (2012) showed that greater accounting expertise on the audit committee leads to greater quality of the internal audit, and, finally, enhances the level of coordination between the external auditors and internal audit function. However, some studies documented contradictory results in which the effective governance mechanisms do not influence the positive outcomes. For example, Carcello, Neal, Palmrose, and Scholz (2011) found that there is no significant association between restatements and audit committee independence or financial expertise. With this conflicting result, the practical significance of the governance mechanisms is questionable.

In sum, most of the studies showed that good governance mechanisms are important to enhance the corporate governance practices. Drawing upon the agency theory, most of these studies illustrate that the key players are effective and make a significant contribution to the corporate governance practices and other possible outcomes. However, the mere existence and other specific features of the governance mechanisms do not really mean that these mechanisms actually fulfil their roles effectively. Furthermore, the studies evidenced conflicting results, which may be due to the different proxies used for measuring the input (e.g. diligence, objectivity) and outcomes (e.g. financial 
reporting quality and audit quality). The proxies used are indirect and have their own limitations, which may affect the findings. Therefore, the scope of the activities of these mechanisms needs to be explored to obtain better insights into the extent and nature of these mechanisms in performing their roles and responsibility. This is supported by prior studies (Beasley et al., 2009; Bluhm, Harman, Lee, and Mitchell, 2011; Turley and Zaman, 2004) that emphasized the need for further investigation of the process and activities of these mechanisms in practice.

\subsection{Process}

The published studies that focus on the process issues in examining the effectiveness of corporate mechanisms, which are largely driven by the qualitative approach, appear to be growing but are still limited (Bluhm, Harman, Lee, and Mitchell, 2011; McNulty et al., 2013). Accordingly, this dearth of studies that explore the process contributes to the lack of understanding about what the key governance mechanisms actually do in practice (Huse, 1998; Brundin and Nordqvist, 2008). The processes of the governance mechanisms in performing their monitoring roles and their activities (such as audit committee meetings, etc.) are deemed important in developing a better understanding of their effectiveness (Gendron et al., 2004). This is further supported by Roberts et al. (2005) who claimed that researching the governance mechanism processes means revealing how they work and providing a better understanding of the concepts of their effectiveness. Therefore, in this section we analyse some of the key insights from studies that addressed the effectiveness of the key governance mechanisms through the process in practice. These studies provide an opportunity to explore the invisible practices of governance mechanisms, and the conditions that support their effectiveness. Overall, these studies show how the process issues might present different scopes of key governance effectiveness from the inputs and outcomes perspectives, which might help to improve our understanding in this area. In order to organize our approach, this section evaluates the extent of the studies that provide evidence concerning the effectiveness of key governance mechanisms in two principle areas: (i) behaviour or conduct of the key players; and (ii) interactions among the key players. Examples of the studies indicated in this principle area are shown in Table 1 below.

\subsubsection{Behaviour and conduct}

Some studies have explored the governance mechanism practices in practical reality by investigating their activities. Essentially, this strand of research looks at the effectiveness of governance mechanisms through their behaviour and conduct in the meetings (e.g. boardroom meetings, audit committee meetings, etc.) or the activities in performing their roles. Using interviews, case studies or observations as the method of study, researchers have collected the data by obtaining the perceptions of the parties involved in the activities. After 
considering the fundamental determinants of the effectiveness of key governance mechanisms through the behaviour and conduct of key players, two factors were derived. In a very general sense, these are (1) power and attributes; and (2) emotions. The effectiveness of the key players depends on how each party exercises their roles and responsibilities; therefore, this study explores specific aspects related to their behaviour and conduct (i.e. power and attributes, and emotions), as there is evidence that these may influence the effectiveness of the key players.

\subsubsection{Power and attributes}

Certain attributes are often considered as significant determinants of the effectiveness of governance mechanisms. For example, previous studies mentioned the importance of expertise, experience and independence in ensuring the effectiveness of the key governance mechanisms in performing their roles (e.g. Salleh et al., 2006; Yatim et al., 2006; Gul and Goodwin, 2010). Similarly, the studies that focused on the process of the corporate governance practices found that these attributes may contribute to the effectiveness of key governance mechanisms. These studies provided some interesting insights. For instance, Cohen, Krishnamoorthy, and Wright (2002) found that auditors perceived audit committees as weak and ineffective in the post-SOX era. Based on their interviews with 36 auditors, the findings of their study indicated that auditors found that audit committee members lacked the necessary expertise, power and scepticism that would make them effective. Even though the members were appointed based on their qualifications, in practice, audit committees were considered to be ineffective in performing their duties, and their existence was symbolic for the purpose of satisfying the regulatory requirements. Similarly, Soobaroyen and Mahadeo (2012) found that the accountability of the board members in Mauritius was questionable, in that the independent non-executive directors were relatively powerless. Although the board members were found to have the required knowledge, the accountability was not practiced by the members in performing their roles. These studies illustrate that the attributes (e.g. knowledge, experience and expertise) alone cannot ensure the effectiveness of the key governance mechanisms.

The key players should have the will to exercise their skills as well as the power to perform their roles (Pettigrew and McNulty, 1995, 1998; McNulty and Pettigrew, 1999). McNulty and Pettigrew (1999) showed how the necessary will and skill in using power by non-executive directors is important in adapting their potential power to actual power. This is supported by O'Higgins (2002) who suggested that the non-executive board members with vast experience are able to provide incisive thinking and argument in performing their roles and responsibility. With their experience, they can recognize the threats and opportunities for the company, which, ultimately, will have a positive impact on company performance. Their effort to come out with the necessary arguments and incisive thinking illustrates their willingness to use the power they have to be effective. 
Similarly, Roberts et al. (2005) found that the willingness of nonexecutives to exercise independence is the key to effective board behaviour. The effectiveness of the board depends on how active and how well the nonexecutive board members use their power in performing their duties. The board members should account for their conduct and have a strong inner consciousness that directs their effectiveness and contributes to the performance of the organization. The findings suggested that independence alone is useless without the willingness of the non-executive members to exercise their power and independence of mind in performing their roles. Therefore, the presence of a culture of openness and the skills of the non-executive board members are required to ensure that they use their power appropriately (McNulty and Pettigrew, 1999; Roberts et al., 2005). The results evidence that traditional divisions between the agency and stewardship theories do not adequately reflect the actual practice of the directors on the board, thereby challenging corporate governance reform as it does not support the actual effectiveness of the boards.

In a related vein, Beasley et al. (2009), Cohen, Krishnamoorthy, and Wright (2010), and Cohen, Hayes, Krishnamoorthy, Monroe, and Wright (2013) also identified the importance of the attributes among the audit committee members in providing insights into their monitoring roles. From the interviews with the audit committee members and auditors, both studies found that the audit committees have the appropriate financial expertise, frequent meetings, and ask challenging questions of management. Likewise, Salleh and Steward (2012) found that the understanding of their responsibilities, awareness of possible issues and the members' accounting and business expertise are the main factors that contribute to the audit committee acting as a mediator in resolving disputes between management and the auditor. More recently, Dobija (2015) supported the importance of having experience and skills among audit committee members to enhance their effectiveness. With adequate knowledge and experience, particularly in the fields of accounting, financial auditing and finance, the audit committee can improve its monitoring control over the external auditor. The findings also documented the power of the audit committee chairman as being a critical factor for an efficient audit committee. The chairman has certain responsibilities, such as setting the agenda, chairing the meeting, giving voice to the members of the audit committee during the meeting, and, in some cases, deciding on the need for and type of voting, thus setting the overall responsibilities of the chairman to ensure the quality of the work performed by the members. With the power that the chairman has, they can give support to other audit committee members and push things forward. Illustrating the efficiency theory (Böhm, Bollen, and Hassink, 2013), the study evidenced that audit committees were first introduced to provide symbolic oversight, and, only later were they found useful for monitoring a company's activities. The study concluded that the perceived efficiency of the audit committee has increased, which is largely associated with the power of the audit committee members. 
Again, these studies highlighted the importance of both the attributes of the audit committee members (e.g. expertise) and their willingness to exercise the power or authority they have (asking probing questions of management in the meeting) in ensuring the effectiveness of the audit committee, which is difficult to observe through a quantitative study. Both power and attributes are required in order to achieve their effectiveness. The findings illustrate the real process in achieving the effectiveness of the key mechanisms and complement most of the evidence in prior studies, which supports the current regulations concerning the composition and role requirements of audit committee members.

\subsubsection{Emotion}

A review of the literature has evidenced the crucial influence of emotion in respect of the effectiveness of key governance players. Emotions may reflect how a person behaves and constitute one of the important motivators of action (Huy, 2002). Huse (1998) found that emotion plays a vital role in board activities, particularly in the relationships among the board chairman, board members and the other parties. Likewise, Samra-Fredericks (2000b) documented that different levels of emotion display an effect in the direction of the board process, thus influencing the effectiveness of its members. Brundin and Nordqvist (2008) conducted an in-depth investigation of the role of the emotions of board members in performing the board's control and service tasks. Based on observations over 18 months, the results revealed that short-term (e.g. anger and surprise) and long-term emotions (e.g. confidence and distrust) are a basis of energy that influences the work of the board and the task performance of its members. In particular, emotion is found to be a source of energy that is reproduced in a process that can affect how the members act in the boardroom and the interaction between board members.

Overall, the emotions of the board members are deemed important in measuring the effectiveness of the board as they can reflect in the board's task performance. The appropriate form of emotion (Hochschild, 1983) can influence the power of board members in performing their roles, and, ultimately, affects their interactions and effectiveness. It is a significant element of the "inner context" of the board itself that can influence the task performance of the board (Pettigrew and McNulty, 1995). These studies look at the different levels of analysis and contexts of board effectiveness. The emotions of the board members are particularly difficult to examine using quantitative methods, and, hence, qualitative methods (observations) can provide more evidence concerning the effectiveness of the board members.

\subsubsection{Interaction}

In addition to the behaviour and conduct, the studies in the literature have also begun to explore the interactions between the parties in understanding their effectiveness in the governance processes. The interaction between these key players can help them to perform their roles in that it enables the exchange of 
knowledge and sharing among members of the organisation (Roberts et al., 2005), and, ultimately, affects their effectiveness. For example, the interactions between the external audit and audit committee not only helps the external auditors in performing the audit, but an effective two-way communication between both parties also assists the audit committee in fulfilling these responsibilities (Gendron et al., 2004; Cohen, Gaynor, Krishnamoorthy, and Wright, 2007; ISA 260). In particular, the external auditor's opinion and information on significant matters, such as financial reporting risks and weaknesses in the internal financial controls, will benefit the audit committee in fulfilling its responsibility (DeZoort, Hermanson, and Houston, 2003; Bedard and Gendron, 2010). Similarly, the internal audit function is an important source of information for audit committees and the external auditor, especially in terms of risk management and internal control (Gramling et al., 2004; Mat Zain and Subramaniam, 2007; Sarens, De Beelde, and Everaert, 2009). Therefore, the interactions between these parties are important to enhance their effectiveness. A few themes are evident in this area of the literature, which include (1) formal and informal interactions; and (2) clear reporting lines.

\subsubsection{Formal and informal interaction}

The performance of the key players and their effectiveness are dependent on the changing relationships and interaction between them (Huse, 1998; Johnson, 2004). Most of the qualitative studies that examined the interactions between key governance mechanisms found that the informal interactions are important in enhancing the effectiveness of the key players. For example, using a longitudinal complete member researcher (CMR) participant observer methodology, Parker (2007b) suggested that the chairing style of the director influences the meeting effectiveness and can make it informal and facilitating. Informality and humour are particularly important in lubricating directors' interrelationships, as well as communication and cohesion, in that they can provide a better environment for information exchange and the sharing of views. This is supported by Gendron and Bedard (2006) who found that informal activities that occurred outside of meetings contribute to the effectiveness of the directors.

Similarly, Turley and Zaman (2007) highlighted the importance of the informal processes in supporting the effectiveness of the audit committee. The study revealed the significance of the informal processes around the audit committee through which concerns might be raised. The operation of the audit committee was most effective as a result of informal communications, rather than through audit committee meetings. Through the voluntary informal communications, the behaviour of the audit committee members has the greatest impact on other organizational participants including senior management, and internal and external auditors. The study revealed that the informal processes and exercise of power are important factors that contribute to the effectiveness of the audit committee. In other words, the personal attributes of the audit committee members in exercising their power, as well the culture of 
encouraging informal interactions, are essential for positive governance outcomes. The findings are consistent with later studies (Sarens, Christopher, and Zaman, 2013; Zaman and Sarens, 2013) concerning the importance of informal interactions that facilitate accessibility to knowledge exchange and sharing between the key players.

Even though informal interaction has been found to be vital, Mat Zain and Subramaniam (2007) found that the internal audit function in Malaysia had limited informal communications and private meetings with audit committee members. Due to the limited private meetings between the parties, the internal auditors cannot share their thoughts and issues concerning the organizations freely with the audit committee. Accordingly, this will affect the effectiveness of both parties in performing their roles and responsibilities, and further supports the importance of the informal interactions between key players to improve their effectiveness. Overall, the measures of effectiveness found in these studies is unlikely to be easily translatable into formal measures of effectiveness, and thus, it is unlikely that the measures reflected in the regulations will increase transparency (Gendron and Bedard, 2006; Mat Zain and Subramaniam, 2007).

\subsubsection{Clear reporting lines}

The studies in the literature also emphasized the importance of clear reporting guidelines, particularly between the internal audit function and the audit committee in order to enhance their effectiveness. Sarens et al. (2009) showed that audit committees seek comfort in terms of the control environment and internal controls through internal auditors. With their knowledge of the organization (e.g. risk management and internal control) and appropriate behavioural skills, internal auditors are able to provide comfort to the audit committee members. The internal audit functions can reduce the discomfort of the audit committee through its advice, and supportive and facilitative roles, such as providing internal audit reports and delivering presentations at audit committee meetings. The findings illustrated the importance of clear reporting guidelines between the internal audit function and audit committee to enhance the effectiveness of both parties.

More recently, Roussy (2013) found a lack of clear reporting lines between the internal audit function and audit committee in public sector organisations. The findings illustrated that the internal audit function perceived that they must prioritize the top manager and be more effective when serving the management instead of the audit committee. This contradicts the current requirement, which requires the internal audit function to report directly to the audit committee instead of to management (see for example BRC, 1999; Smith Committee, 2003; Finance Committee on Corporate Governance, 2007). Studies have highlighted some of the findings that contrast with commonly assumed views on the interactions between internal audit functions and audit committees (e.g. Gendron and Bedard, 2006; Sarens et al., 2009). It is acknowledged that the non-executive members have vast experience and skills, however, they may 
have inadequate knowledge and be unfamiliar with the operations of the organisations. Thus, the strong internal audit function and frequent interactions with the internal audit function are deemed important for the audit committee to improve its effectiveness as the internal audit function may provide the information to the audit committee members.

In general, with the increased importance of the relationship and interactions between key governance mechanisms in today's environment, deeper interactions among the key governance players are essential to improve their effectiveness. As proven in prior studies, the interactions between the internal audit function and audit committee in terms of clear reporting guidelines is essential to improve their effectiveness. Both parties should work together in performing their roles to enhance their effectiveness.

Table 1: Qualitative studies on corporate governance effectiveness in the literature

\begin{tabular}{lll}
\hline Source & Context & Principle Area \\
\hline $\begin{array}{l}\text { O'Higgins } \\
(2002)\end{array}$ & Board of directors & $\begin{array}{l}\text { Behaviour and } \\
\text { conduct }\end{array}$ \\
$\begin{array}{l}\text { Cohen et al. } \\
(2002)\end{array}$ & Audit committee & $\begin{array}{l}\text { Behaviour and } \\
\text { conduct }\end{array}$ \\
$\begin{array}{l}\text { Roberts et al. } \\
(2005)\end{array}$ & Board of directors & $\begin{array}{l}\text { Behaviour and } \\
\text { conduct }\end{array}$ \\
\hline
\end{tabular}

$\begin{array}{lll}\begin{array}{l}\text { Gendron and } \\ \text { Bedard (2006) }\end{array} & \text { Audit committee } & \begin{array}{l}\text { Behaviour and } \\ \text { conduct }\end{array}\end{array}$

Parker (2007) Board of directors Behaviour and conduct

Turley and Zaman (2007)

Zain and

Subramaniam (2007)

Audit committee Interactions
Audit committee and internal audit function

Findings and Results

The most important characteristics of effective non-executive directors are: (i) incisive thinking, the ability to size up a complex issue clearly, (ii) the ability to make a beneficial contribution to the company inside and outside the boardroom, and (iii) practical business experience. Audit committee is typically ineffective and lacks sufficient power to be a strong governance mechanism.

- Non-executives' willingness to exercise their independence is the key to effective board behaviour.

- The culture of openness and the skills of the nonexecutive board members are required to ensure that they use their power effectively.

- Audit committee effectiveness is constructed through four categories of process - background, ceremonial features, reflective interpretations of substantive practices and activities taking place during audit committee meetings, and reflective understanding of informal practices taking place outside meetings.

- Boardroom culture emerges as a potent ingredient in the governance process.

- Informality and humour are important in lubricating director's interrelationship, communication and cohesion. - The importance of informal processes around the AC.

- Possibility that the AC's impact on governance may be greatest in non-routine situations. - Audit committee influence on power relations between organizational participants.

- Indicate infrequent informal communications and limited private meetings between the HIAFs and $\mathrm{ACs}$, and a need for clear reporting lines. - ACs are seen to be held in high esteem for their authority and are expected to take on greater leadership in the inquiry of management's decision-making. 
Table 1: Continued

\begin{tabular}{lll}
\hline Source & Context & Principle Area \\
\hline $\begin{array}{l}\text { Brundin and } \\
\text { Nordqvist }\end{array}$ & Board of directors & Interactions \\
& & \\
& & \\
$\begin{array}{l}\text { Beasley et al. } \\
(2009)\end{array}$ & Audit committee & $\begin{array}{l}\text { Behaviour and } \\
\text { conduct }\end{array}$ \\
& & \\
\hline
\end{tabular}

Sarens et al. (2009)

Cohen et al. (2010)

Soobaroyen and Mahadeo (2012)

Salleh and Stewart (2012)

Cohen et al. (2013)

Roussy (2013)
Audit committee and internal audit function

External audit and audit committee

Board of directors

Behaviour and conduct

Audit committee

Behaviour and conduct

Audit committee

Internal audit function

Interactions

Behaviour and conduct
Findings and Results

- Empirical accounts from board meetings and diary notes from a CEO show in detail how emotions work as power energizers and status energizers in boardroom dynamics.

- Short-term as well as long-term emotions are a source of energy that affects board work, and that are influential in the board members' task performance.

- AC members strive to provide effective monitoring of financial reporting and seek to avoid serving on ceremonial AC.

- Responses vary with personal and company characteristics, with particularly notable differences related to AC members' accounting expertise and time of appointment to the $\mathrm{AC}$ (preSOX versus post-SOX). - Audit committees seek comfort with respect to the control environment and internal controls; two areas in which they confront considerable discomfort.

- Internal audit function's traditional assurance role, its involvement in improving internal controls provides a significant level of comfort to the audit committee.

- Internal auditors' unique knowledge about risk management and internal control, combined with appropriate inter-personal and behavioural skills, enable them to provide this comfort.

- AC are seen as having sufficient expertise and power to fulfil their responsibilities.

- There is a strong, positive shift post-SOX in the seriousness that AC members bring to their role as monitors of the quality of the financial reporting process

- Board accountability is noted as affecting board effectiveness.

- Board members' selection process is important in determining their accountability to ensure effective company oversight.

- When the issue is very material, the audit committee plays a mediating role as a third-party intermediary that provides assistance to resolve disputes.

- The authority of the committee to act as a mediator comes from its oversight responsibilities, its understanding and awareness of possible issues and the members' accounting and business expertise.

- SOX has positively impacted the monitoring role of the audit committee (board), which directors attributed to the financial expertise and internal control requirements, and heightened substantive diligence.

- Internal auditors consider that their primary role is to serve the top manager and the organization and that they must prioritize the top manager at the expense of audit committee members. 
Table 1: Continued

\begin{tabular}{|c|c|c|c|}
\hline Source & Context & Principle Area & Findings and Results \\
\hline Dobija (2015) & Audit committee & $\begin{array}{l}\text { Behaviour and } \\
\text { conduct }\end{array}$ & $\begin{array}{l}\text { - For ACs to efficiently perform their } \\
\text { responsibilities, they must have access to greater } \\
\text { resources that would provide them with a greater } \\
\text { degree of independence in performing the } \\
\text { functions entrusted to them. } \\
\text { - Those who are exercising control over the } \\
\text { auditor should have adequate knowledge, } \\
\text { experience and skills in the fields of accounting, } \\
\text { financial auditing and finance. }\end{array}$ \\
\hline
\end{tabular}

\section{Discussion}

Recent qualitative corporate governance research has answered calls to go beyond the compositions and outcomes of key governance players in evaluating the effectiveness of the key players. The discussion in the previous section illustrates that scholars have started to explore a few areas concerning the processes in governance through observations and consider the perceptions of the key players and related parties. These studies focus more on their inner working processes in terms of their behaviour and conduct, and the interaction between them and with other parties. Instead of looking at the characteristics (e.g. competency, skills, experience, etc.) or outcomes (e.g. financial reporting quality, corporate performance, etc.) alone, researchers have looked at the processes in which how the key governance players perform their roles is observed to understand their effectiveness. The literature provides evidence that the actual effectiveness of corporate mechanisms depends upon the behavioural and conduct process, and how the relationships and interactions between key governance mechanisms are developed in a particular organization context. Scholars also document various factors that may affect the behaviour and interactions between key players, which, ultimately, affects their effectiveness.

Based on the literature, it is suggested that in creating effective governance mechanisms, a company should not only look at the characteristics of the mechanisms (e.g. independence, knowledge) but should also look at the culture, the informal activities and their willingness to play an active role in the governance. For example, the board should play its role properly in the boardroom to ensure that the organisation can practice good governance. Boards have an obligation to ensure proper and active participation in the boardroom and each key player should play their role effectively. Apart from the independent members with the right skills on the board, the board members and other key players should play an active role in the meetings (see for example Gendron and Bedard, 2006; Parker, 2007b; Cohen et al., 2010). Roberts et al. (2005) argued that expertise and independence of the board members are only significant if the members have a willingness to exercise their power and be active to be effective. Therefore, for such a process to work, the board needs to create a culture that will boost its effectiveness. The emotions of the governance mechanisms are also important as these will influence the interactions of the 
mechanisms, and, ultimately, their effectiveness (Brundin and Nordqvist, 2008). The findings of these studies give different contexts of the effectiveness of governance mechanisms, which are not publicly observable by the stakeholders.

Another process context that qualitative researchers have looked at in exploring the effectiveness of governance mechanisms is the interaction between the key mechanisms. Together with the increased importance of the relationship and interaction between key governance mechanisms (e.g. internal audit function and audit committee) in today's environment, deeper interaction among the key governance players is essential to improve their effectiveness. As proven in prior studies (e.g. Mat Zain and Subramaniam, 2007; Turley and Zaman, 2007; Sarens et al., 2009; Sarens et al., 2013; Zaman and Sarens, 2013), the interaction between the internal audit function and audit committee in terms of clear reporting guidelines is essential to improve their effectiveness. Both parties should work together in performing their roles and the interaction should not focus solely on the formal interaction as the findings of the studies show that informal interaction is clearly important to enhance their effectiveness. Thus, in supporting the informal interaction among the parties, the culture of the governance practices in the organisations is important.

The studies contribute to a limited but developing pool of research that employs a qualitative approach in understanding the effectiveness of the mechanisms through the corporate governance processes and practices. Furthermore, complementing the findings in the quantitative studies, the findings of these studies have deepened our understanding of the effectiveness of the governance mechanisms. Whilst the characteristics of the governance mechanisms influence their effectiveness, it is the actual conduct of the key governance players that determines their effectiveness, and which ultimately affects the outcomes. Based on the discussion in the literature, the behaviour and conduct, and the interaction of the key governance mechanisms in the processes will influence their effectiveness.

\section{Conclusion}

The key governance players (e.g. board of directors, audit committee, internal audit and external audit) are important in ensuring better corporate governance practices. This paper presents a review of the literature concerning the effectiveness of these key players. The study contributes to the literature by providing fundamental findings concerning the effectiveness of corporate governance mechanisms related to the input and outcomes of the effectiveness of the key players, as well as across different aspects of the processes that affect their effectiveness (behaviour or conduct of the key players; and interactions among key players). The study extends prior studies by simultaneously discussing the effectiveness of all key players. Furthermore, in advancing the understanding concerning the effectiveness of key players, the study offers suggestions for future research, particularly in respect of the process issue. Therefore, this study should be useful to academic researchers, practitioners, 
regulators, and others who are interested in understanding the effectiveness of key players.

Based on the studies discussed in the literature, the researchers examined the effectiveness of the corporate governance mechanisms from three perspectives - the inputs, process and outcomes. Based on the studies in the literature, the inputs and outcomes of the effectiveness of the mechanisms are largely driven by quantitative studies. Whilst the studies on the processes and activities of the governance mechanisms in delivering their roles tend to be driven by qualitative studies. The studies deepen our understanding about the factors that contribute to the effectiveness of the mechanisms, the processes that affect their effectiveness as well as the impact of their effectiveness. The studies complement each other, and give a broader understanding and knowledge concerning the effectiveness of the governance mechanisms. However, as some researchers argued that the studies that focus on the process issues in this area are rather limited (Brennan and Solomon, 2008; Christopher, 2010), the need for more studies on the process issues in this area, possibly by employing qualitative methodologies to contribute to the understanding of the process and influences of the effectiveness of the governance mechanisms, are deemed necessary (Daily, Dalton, and Cannella, 2003; Roberts et al., 2005; Parker, 2007b; McNulty et al., 2013).

\subsection{Direction for Future Research}

Despite the volume of research on key governance effectiveness, there is still much room for future research. Such research could address the behaviour or conduct and interaction in practice, which potentially affect the effectiveness of the key players. The examples provided below are some new areas of research that could be considered by future researchers.

Investigating the processes of the corporate governance practices may be difficult and challenging, however, the findings and results hold significant promise for improving corporate governance practices (Johnson, 2004; Parker, 2007b). The studies on the process issues highlight the importance of investigating the effectiveness of the governance mechanisms within the organizational context and practices, and consider the various factors that could influence their effectiveness. Thus, by examining the governance processes, the decision process by the users of the governance information or stakeholders may be significantly improved. Therefore, more research in the field of corporate governance process, and particularly the effectiveness of governance mechanisms, is necessary to discern what and how the actual conduct of the governance mechanisms can support their effectiveness. It is also suggested that governance researchers consider the international dimensions. Due to the institutional differences and variations in corporate governance systems globally, the processes and the activities of governance mechanisms may be influenced by cultural values and norms. Developing countries, for instance have a different culture than developed countries. Owing to such differences, governance scholars can make interesting contributions by understanding the 
processes of the governance practices in measuring the effectiveness of key players.

Recognizing the limited studies in the interaction process, another opportunity for researchers to broaden the study of the effectiveness of corporate governance mechanisms is to simultaneously consider the dynamics of the interactions among the various key players, including the external auditor, internal audit function, audit committee and board of directors, and how the interactions can influence their effectiveness. The interconnected relationships and interactions of these key players is assumed to influence the effectiveness of the mechanisms and powerful governance practices. Thus, there is a call for greater and more detailed attention of the interaction processes and dynamics to better understand how these affect the effectiveness of governance mechanisms. Understanding the proper processes of the interactions among key mechanisms is an obvious and vital focus for future qualitative governance studies. Addressing the lack of studies on the effectiveness of the external audit, future studies may focus on how the interactions between the key governance mechanisms may influence the external audit process, such as judgement in the audit process, risk assessment of the external auditor, or the process of obtaining and evaluating evidence. The study may have some implications that might be relevant both academically and practically. The evidence may be useful to establish confidence among the stakeholders by incorporating the attributes and practices that are found to be relatively important for effective governance.

\section{References}

Abbott, L. J., Parker, S., \& Peters, G. F. (2004). Audit Committee Characteristics and Restatements. Auditing: A Journal of Practice \& Theory, 23(1), 69-87.

Abbott, L. J., Parker, S., Peters, G. F., \& Raghunandan, K. (2003). The Association between Audit Committee Characteristics and Audit Fees. Auditing: A Journal of Practice and Theory, 22(2), 17-32.

Albrecht, W. S., Howe, K. R., Schueler, D. R., \& Stocks, K. D. (1988). Evaluating the Effectiveness of Internal Audit Departments. Altamonte Springs, FL: The Institute of Internal Auditors Research Foundation.

Bailey, A. D. J., Gramling, A. A., \& Ramamoorti, S. (2003). Research Opportunities in Internal Auditing. Altamonte Springs, FL: Institute of Internal Auditors Research Foundation.

Bame-Aldred, C. W., Brandon, D. M., Messier, W. F., Rittenberg, L. E., \& Stefaniak, C. M. (2013). A Summary of Research on External Auditor Reliance on the Internal Audit Function. Auditing: A Journal of Practice \& Theory, 32(Supplement 1), 251-286.

Beasley, M. S., Carcello, J. V., Hermanson, D. R., \& Lapides, P. D. (2000). Fraudulent financial reporting: consideration of industry traits and corporate governance mechanisms. Accounting Horizons, 14, 441-454. 
Beasley, M. S., Carcello, J. V., Hermanson, D. R., \& Neal, T. L. (2009). The Audit Committee Oversight Process. Contemporary Accounting Research, 26(1), 65-122.

Beattie, V., \& Fearnley, S. (2002). Auditor independence and non-audit services: A literature review.

Bedard, J., Chtourou, S. M., \& Courteau, L. (2004). The effect of audit committee expertise, independence and activity on aggressive earnings management. Auditing: A Journal of Practice \& Theory, 23(2), 13-35.

Bedard, J., \& Gendron, Y. (2010). Strengthening the Financial Reporting System: Can Audit Committees Deliver? International Journal of Auditing, 1-37.

Bluhm, D., Harman, W., Lee, T. W., \& Mitchell, T. R. (2011). Qualitative research in management: A decade of progress. Journal of Management Studies, 48, 1866-1891.

Bo"hm, F., Bollen, L. H., \& Hassink, H. F. (2013). Spotlight on the design of European ACs: A comparative descriptive study. International Journal of Auditing, 17(2), 138-161.

Bradbury, M. E., Mak, Y. T., \& Tan, S. M. (2004). Board characteristics, audit committee characteristics and abnormal accruals. Retrieved from http://ssrn.com/abstract=535764 website:

Brennan, N., \& Solomon, J. (2008). Corporate governance, accountability and mechanisms of accountability: an overview. Accounting, Auditing and Accountability Journal, 21(7), 885-906.

Brown, L., \& Caylor, M. (2006). Corporate Governance and Firm Valuation. Journal of Accounting and Public Policy, 25, 904-934.

Brundin, E., \& Nordqvist, M. (2008). Beyond facts and figures: the role of emotions in boardroom dynamics. Corporate Governance: An International Review, 16(4), 326-341.

Carcello, J. V., Hermanson, D. R., \& Riley, R. A. (2002). Board characteristics and audit fees. Contemporary Accounting Research, 19(3), 365-384.

Carcello, J. V., Hermanson, D. R., \& Ye, Z. (2011). Corporate Governance Research in Accounting and Auditing: Insights, Practice Implications, and Future Research Directions. Auditing: A Journal of Practice \& Theory, 30(3), 1-31.

Carcello, J. V., \& Nagy, A. L. (2004). Audit firm tenure and fraudulent financial reporting. Auditing: A Journal of Practice \& Theory, 23(2), $55-69$.

Carcello, J. V., Neal, T. L., Palmrose, Z. V., \& Scholz, S. (2011). CEO involvement in selecting board members, audit committee effectiveness, and restatements. Contemporary Accounting Research, 28(2), 396-430.

Carey, P., \& Simnett, R. (2006). Audit partner tenure and audit quality. The Accounting Review, 81(3), 653-676. 
Chaunrommanee, W., \& Swierczek, F. W. (2007). Corporate Governance in ASEAN Financial Corporations: Reality or Illusion? Corporate Governance: An International Review, 15(2), 272-283.

Christopher, J. (2010). Corporate governance - a multi-theoretical approach to recognizing the wider influencing forces impacting on organizations. Critical Perspectives on Accounting, 21(8), 683-695.

Christopher, J., Sarens, G., \& Leung, P. (2009). A critical analysis of the independence of the internal audit function: evidence from Australia. Accounting, Auditing \& Accountability Journal, 22(2), 200-220.

Clark, M., Gibbs, T., \& Schroeder, R. (1981). CPAs judge internal audit department objectivity. Management Accounting, 62(8), 40-43.

Cohen, J. R., Gaynor, L. M., Krishnamoorthy, G., \& Wright, A. M. (2007). Auditor Communications with the Audit Committee and the Board of Directors: Policy Recommendations and Opportunities for Future Research. Accounting Horizons, 21(2), 165-187.

Cohen, J. R., Hayes, C., Krishnamoorthy, G., Monroe, G. S., \& Wright, A. M. (2013). The Effectiveness of SOX Regulation: An Interview Study of Corporate Directors. Behavioral Research in Accounting, 25(1), 61-87.

Cohen, J. R., Krishnamoorthy, G., \& Wright, A. (2004). The Corporate Governance Mosaic and Financial Reporting Quality. Journal of Accounting Literature, 87-152.

Cohen, J. R., Krishnamoorthy, G., \& Wright, A. (2010). Corporate Governance in the Post-Sarbanes-Oxley Era: Auditors' Experiences. Contemporary Accounting Research, 27(3), 751-786.

Cohen, J. R., Krishnamoorthy, G., \& Wright, A. M. (2002). Corporate governance and the audit process. Contemporary Accounting Research, 19(4), 573-594.

Coram, P., Ferguson, C., \& Moroney, R. (2008). Internal Audit, Alternative Audit Structures and the Level of Misappropriation of Assets Fraud. Accounting and Finance, 48(4), 543-559.

Daily, C., Dalton, D. R., \& Cannella, A. A. (2003). Corporate Governance: Decades of Dialogue and Data , 28(3), pp. 371-383. Academy of Management Review, 28(3), 371-383.

Destefanis, S., \& Sena, V. (2007). Patterns of corporate governance and technical efficiency in Italian manufacturing. Mangerial and Decision Economics, 28, 27-40.

DeZoort, F. T., Hermanson, D. R., Archambeault, D. S., \& Reed, S. A. (2002). Audit committee effectiveness: A synthesis of the empirical audit committee literature. Journal of Accounting Literature, 21, 38-75.

DeZoort, F. T., Hermanson, D. R., \& Houston, R. W. (2003). Audit Committee Member Support for Proposed Audit Adjustments: A Source Credibility Perspective. Auditing: A Journal of Practice \& Theory, 22(2), 189-205. 
Dobija, D. (2015). Exploring audit committee practices: oversight of financial reporting and external auditors in Poland. Journal of Management and Governance, 19, 113-143.

Gendron, Y., \& Bedard, J. (2006). On the constitution of audit committee effectiveness. Accounting, Organizations and Society, 31, 211-239.

Gendron, Y., Bedard, J., \& Gosselin, M. (2004). Getting Inside the Black Box: A Field Study of Practices in "Effective" Audit Committees. Auditing: A Journal of Practice \& Theory, 23(1), 153-171.

Goodwin-Stewart, J., \& Kent, P. (2006). The relation between external audit fees, audit committee characteristics and internal audit. Accounting and Finance, 46(4), 387-404.

Gramling, A. A., Maletta, M. J., Schneider, A., \& Church, B. K. (2004). The Role of The Internal Audit Function in Corporate Governance: A Synthesis of the Extant Internal Auditing Literature and Directions for Future Research. Journal of Accounting Literature, 23, 194-244.

Gul, F. A., \& Goodwin, J. (2010). Short-term debt maturity structures, credit ratings, and the pricing of audit services. The Accounting Review, 85(3), 877-909.

He, J., \& Huang, Z. (2011). Board informal hierarchy and firm financial performance - Exploring a tactic structure guiding boardroom interactions. Academy of Management Journal, 54, 1119-1139.

Hochschild, A. R. (1983). The Managed Heart. Commercialization of Human Feeling. Los Angeles: University of California Press.

Hsu, H.-E. (2008). Audit committees in US entrepreneurial firms. Journal of American Academy of Business, 13(1), 121-127.

Huse, M. (1998). Researching the Dynamics of Board-Stakeholder Relations. Long Range Planning, 31(2), 218-226.

Huy, Q. N. (2002). Emotional Balancing of Organizational Continuity and Radical Change: The Contribution of Middle Managers. Administrative Science Quarterly, 47(1), 31-69.

Johnson, P. (2004). Shared thinking and interaction in the family business boardroom. Corporate Governance: The Journal for Effective Board Behaviour, 4, 39-51.

Jonh, K., \& Senbet, L. (1998). Corporate Governance and Board Effectiveness. Journal of Banking and Finance, 22, 371-403.

Klein, A. (2002a). Audit committee, board of director characteristics, and earnings management. Journal of Accounting \& Economics, 33, 375400.

Knechel, W. R., \& Vanstraelen, A. (2007). The relationship between auditor tenure and audit quality implied by going concern opinions. Auditing: A Journal of Practice and Theory, 26, 113-131.

Krishnamoorthy, G., \& Maletta, M. (2012). The Role of Internal Audit in the Financial Statement Audit: The Contingent Effects of Board Independence and Audit Committee Effectiveness. Northeastern University. 
Machold, S., \& Farquhar, S. (2013). Board task evolution: a longitudinal field study in the UK. Corporate Governance: An International Review, 21, 147-162.

Marsh, H. L., \& Powell, T. E. (1989). The Audit Committee Charter: Rx for Fraud Prevention. Journal of Accountancy, February, 5-57.

Mat Zain, M., \& Subramaniam, N. (2007). Internal Auditor Perceptions on Audit Committee Interactions: A Qualitative Study in Malaysian Public Corporations. Corporate Governance: An International Review, 15(5), 894-908.

McDaniel, L., Martin, R. D., \& Maines, L. A. (2002). Evaluating financial reporting quality: The effects of financial expertise versus financial literacy. The Accounting Review(Supplement), 139-167.

McNulty, T., \& Pettigrew, A. M. (1999). Strategists on the board. Organisation studies, 20(1), 47-74.

McNulty, T., Zattoni, A., \& Douglas, T. (2013). Developing Corporate Governance Research through Qualitative Methods: A Review of Previous Studies. Corporate Governance: An International Review, 21(2), 183-198.

Misangyi, V. F., \& Acharya, A. G. (2014). Substitutes or Complements? A Configurational Examination of Corporate Governance Mechanisms. Academy of Management Journal, 57(6), 1681-1705.

Mitton, T. (2002). A Cross-Firm Analysis of the Impact of Corporate Governance on the East Asian Financial Crisis. Journal of Financial Economics, 64(2), 215-241.

O'Higgins, E. (2002). Non-executive directors on boards in Ireland: co-option, characteristics and contributions. Corporate Governance: An International Review, 10(1), 19-28.

Parker, L. D. (2007b). Internal governance in the nonprofit boardroom: a participant observer study. Corporate Governance: An International Review, 15(5), 923- 934.

Pettigrew, A. M., \& McNulty, T. (1995). Power and Influence in and around the Boardroom. Human Relations, 48(845-873).

Pettigrew, A. M., \& McNulty, T. (1998). Sources and Uses of Power In and Around the Boardroom. European Journal of Work and Organisational Psychology, 7(2), 197-214.

Prawitt, D. F., Smith, J. L., \& Wood, D. A. (2009). Internal Audit Quality and Earnings Management. The Accounting Review, 84(4), 1255-1280.

Pugliese, A., Nicholson, G., \& Bezemer, P.-J. (2015). An Observational Analysis of the Impact of Board Dynamics and Directors' Participation on Perceived Board Effectiveness. British Journal of Management, 26, $1-25$.

Roberts, J., McNulty, T., \& Stiles, P. (2005). Beyond agency conceptions of the work of the nonexecutive director: Creating accountability in the boardroom. British Journal of Management, 16, S5-S26. 
Roussy, M. 1. (2013). Internal auditors' roles: From watchdogs to helpers and protectors of the top manager. Critical Perspectives on Accounting, 24, 550-571.

Salleh, Z., \& Steward, J. (2012). The Role of the Audit Committee in Resolving Auditor-Client Disagreements: A Malaysian Study. Accounting, Auditing \& Accountability Journal, 25(8), 1340-1372.

Salleh, Z., Steward, J., \& Manson, S. (2006). The impact of board composition and ethnicity on audit quality: Evidence from Malaysian companies. Malaysian Acccounting Review, 5(2), 61-83.

Samra-Fredericks, D. (2000b). An analysis of the behavioural dynamics of corporate governance $-A$ talk-based ethnography of a UK manufacturing "board-in-action". Corporate Governance: An International Review, 8, 311-326.

Sarens, G., Christopher, J., \& Zaman, M. (2013). A Study of the Informal Interactions between Audit Committees and Internal Auditors in Australia. Australian Accounting Review, 23(4), 307-329.

Sarens, G., De Beelde, I., \& Everaert, P. (2009). Internal Audit: A Comfort Provider to the Audit Committee. The British Accounting Review, 1-17.

Soobaroyen, T., \& Mahadeo, J. D. (2012). Do corporate governance codes improve board accountability? Evidence from an emerging economy. Qualitative Research in Accounting \& Management, 9(4), 337-362.

Spira, L. F. (2006). Black boxes, red herrings and white powder: UK Audit Committees in the 21st Century. Journal of Banking Regulation, 7(1/2), 180-188.

Stewart, J., \& Munro, L. (2007). The impact of audit committee existence and audit committee meeting frequency on the external audit: Perceptions of Australian auditors. . International Journal of Auditing, 11(1), 5169.

Suwaidan, S., \& Qasim, A. (2010). External Auditors' Reliance on Internal Auditors and Its Impact on Audit Fees: An Empirical Investigation. Managerial Auditing Journal, 25(6), 509-525.

Turley, S., \& Zaman, M. (2004). The Corporate Governance Effects of Audit Committees. Journal of Management and Governance, 8, 305-332.

Turley, S., \& Zaman, M. (2007). Audit committee effectiveness: informal processes and behavioural effects. Accounting, Auditing \& Accountability Journal, 20(5), 765-788.

Yatim, Kent, P., \& Clarkson, P. (2006). Governance structure, ethnicity, and audit fees of Malaysian listed firms. Managerial Auditing Journal, 21(7), 757-782.

Zaman, M. (2001). Turnbull - Generating Undue Expectations of the Corporate Governance Role of Audit Committees. Managerial Auditing Journal, 16(1), 5-9.

Zaman, M., \& Sarens, G. (2013). Informal Interactions Between Audit Committees And Internal Audit Functions: Exploratory Evidence And 
Effectiveness of Corporate Governance Mechanisms: A Review of the Literature

Directions For Future Research. Managerial Auditing Journal, 28(6), $1-30$. 